Raffé suggested various inquiries bearing on the effect of colour, and the influence of light on certain metals. Mr. A. Cunnington referred to problems arising in connexion with the passage of railway trains through short tunnels, as illustrating the liability of temporary dazzling of the eyes to cause accidents. Mr. P. J. Waldram discussed the problem of avoiding troublesome reflections in picture galleries, referring particularly to the effect of badly placed skylights.

At the end of the discussion Mr. L. Gaster explained the interlinking of the Illumination Research Committee with the various other organisations interested in research on illumination, and pointed out that the Illuminating Engineering Society is performing valuable service by acting as a 'liaison officer' and as a clearing-house for information. The recent discussion before the Society of the specifications of the various B.E.S.A. committees (see NATure, March I3, p. 397) proved valuable in making them more widely known, and it is hoped that the discussion of this preliminary report of the Illumination Research Committee would be equally useful. It is of obvious importance that reports of such work should receive the widest publicity and should be thoroughly discussed, and he hoped that the forthcoming reports on individual researches would be likewise presented at meetings of the Society for full consideration.

\title{
Primitive Time Reckoning and the Calendar.
}

THE stages by which the Julian calendar as a method of time reckoning was attained are demonstrated by Dr. Martin P. Nilsson in a contribution to vol. 39 , pt. 6 of Scientia, which surveys the various methods of measuring time employed by primitive and early peoples, and shows how the conception of a continuum in time, which is the essence of a calendar, has gradually developed.

The mind of primitive man, being essentially interested in the concrete, expresses time in terms of action, such as the time it takes to cook a bowl of rice, or the duration of a journey, the double hour of the Babylonians being an example of the latter. In the early stages certain recurrent natural phenomena are regarded, not as units of time of a certain duration, but as indications of time. The conception of continuity is absent at this stage. Thus time of day is indicated by the natural divisions-dawn, twilight, sunrise, or the position of the sun. Night is regarded as a whole. The crow of the cock is employed generally, but few make use of the stars as did the South American Indians and the Homeric Greeks. The conception of a 24 hours' day is late.

In the same way, the season of the year is indicated by natural phenomena, winter, summer, the season of snow, rain, drought. Neither the duration of the season nor, more remarkable, their number, is uniform. While we have four seasons, other peoples have two, three, five, or six. The unity of the year is established only slowly, and that empirically. As among the Banyankole, the reckoning may be from rains to rains. An agricultural people employs the agricultural operations, reckoning from sowing to harvest, the vacant period following the latter not counting.

The year is recorded and identified by some striking happening such as the "year of the meteorites." The Roman method of identifying it by the Consuls is another example.

The observation of the stars and constellations, and especially their heliacal rising, gives a more exact method of time reckoning. These observations are brought into relation with agricultural operations. This leads to the observation of the solar year, which in Egypt was fixed so far back as the prehistoric period through observation of the heliacal rising of Sirius; but the conception of units of time and time as a continuum arose from observation of the moon's phases, which gave the lunar month and the divisions of the lunar month as a record of time within the month. These months were named from the appropriate activities or natural phenomena. Owing to the disparity of the lunar month and the solar year in this luni-solar year, which was known to the Greeks, Babylonians, and Jews, it became necessary, whether the cycle consisted of 12 or 13 lunar months, to employ the principle of inter- or extra-calation, either at irregular intervals or periodically, as was done in Greece in the $7^{\text {th }}$ century B.C. It was this last type of calendar which was superseded by Cæsar's reform, which based the Julian calendar solely on the solar year, recognising the impossibility of equating it with the lunar year.

\section{The Need for Precision in Botanical Terminology.}

$\mathrm{N}$ his presidential address to the Linnean Society on May 27, Dr. A. B. Rendle referred to the work of the Society during the year. An interesting feature of certain of the discussions has been the tendency to get back to first principles or definitions and to discover that that which we had regarded as definite is after all vague. For example, in one of the discussions various authorities were quoted in support of different ideas as to the conception of the term carpel. Morphological terms originate in a: desire to express certain conceptions, limited or general, and morphologists are apt to find themselves in the same position as the present-day systematist in typifying species. In the matter of definitions a meaning may be attached to a term which the originator never meant to convey; moreover, a vague use of terms may engender vague ideas of relationship. The advisability of the inclusion of the seed-like organs of Pteridosperms under the definition of seeds was also questioned. What is the degree of importance of the differences between the modern seed, which has priority for the use of the term, and the organ characteristic of Pteridosperms? Has the latter advanced beyond the gametophyte stage? Does the fact that postponement of embryo-formation until after the freeing of the seed occurs, for example in Cycads, meet the objection ? This absence of an embryo may be called negative evidence; but is it not rather the absence of the criterion of the normal seed, which is an arrangement for the protection of the new sporophyte during a period of rest or transport? The phases in the life-history preceding and accompanying germination must have been widely different in the two great groups.

Until the Caytoniales were described we were clear as to what we understood by Angiosperms. We know nothing of the contents of the seed-like bodies in this primitive group, but we recognise the Angiosperm idea and associated with it the generally considered advanced character of wind-pollination.

Are we clear as to our ideas of what constitutes a Gymnosperm? The tendency is to include here

NO. 2959, VOL. I I 8 ] 